\title{
Simulation of Disassembly and Re-assembly Processes with Beta-distributed operation Times
}

\author{
Jörg Fischer, Patricia Stock and Gert Zülch \\ University of Karlsruhe, ifab-Institute of Human and Industrial Engineering, Kaiserstrasse \\ 12, D-76131 Karlsruhe, Germany. \\ Email: \{joerg.fischer, patricia.stock, gert.zuelch\}@ifab.uni-karlsruhe.de
}

\begin{abstract}
In the case of designing or improving industrial disassembly and repair shops, a special characteristic to be considered is the stochastic nature of disassembly, diagnosis and re-assembly times. Because of this special characteristic, the reorganisation of such work systems shall be supported by using a simulation method which considers distributed operation times. A question to be answered is the type of distribution which should be used. The problem is that during the data collection phase of a simulation project, the parameters of the often suggested Normal- or Gamma-distribution are normally not available. In contrary the parameters of the Beta-distribution are easy to get, because it could be characterised by the optimistic, the pessimistic and the most common time value. The following investigates in which way the different distributions effect the quantitative evaluation of a modelled repair shop compared with fixed operation times. Finally disadvantages and advantages of the use of different distributions in a simulation study will be discussed.
\end{abstract}

Key words: Simulation, Stochastic operation times, Beta-Distribution, Disassembly

\section{INTRODUCTION TO THE PROBLEM}

For the design and control of production systems simulation has proven to be a powerful tool. When designing or improving industrial disassembly and repair shops, a special problem to be considered is the feasibility of these operations and the stochastic nature of disassembly, diagnosis and reassembly times. 
In order to take the latter into account, the re-organisation of these kinds of work systems shall be supported by using a simulation approach which can realise stochastic execution times (with respect to feasibility of disassembly operations refer to SCHILLER (1998, pp. 25). Furthermore, it is necessary to consider which type of distribution is particularly suitable for the simulation of execution times.

\section{OBJECT-ORIENTED SIMULATION}

The simulation tool OSim which is used here, was developed at the ifabInstitute of Human and Industrial Engineering of the University of Karlsruhe (JONSSON 2000, p. 181; ZÜLCH et al. 2000; ZÜLCH, FISCHER 2002). The modelling of enterprise processes based on activity networks were studied by Johnson (JONSSON 2000). Activity networks are graphs with a logical sequence of activities, which can be used in the description of production and service processes (GROBEL 1992, p. 26). The production or service system to be modelled can thus be considered as a collection of activity networks, with whose help all processes occurring in the system can be modelled. An exemplary activity network is shown in Figure 1.
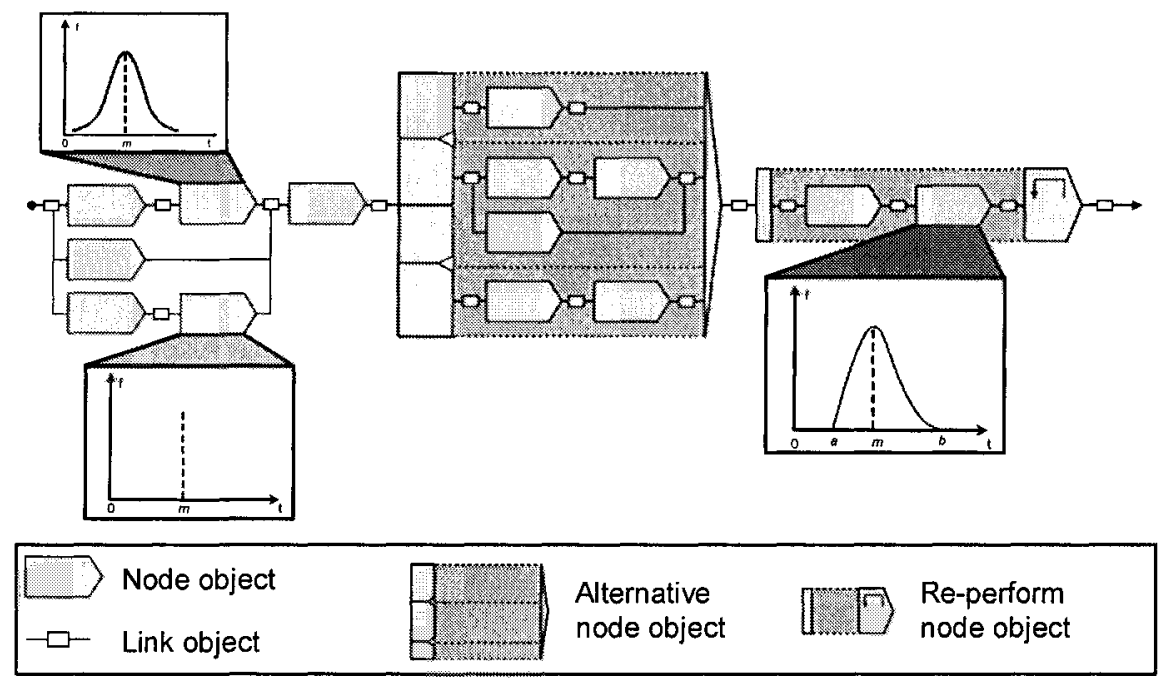

Figure 1. Example of an activity network with stochastic activity duration

Each node represents an activity executed within the process. Usually the nodes are connected with a conjunction, i.e. every activity will be executed exactly one time (for every triggering). This way of modelling the enterprise 
processes is quite common for a production process, however another logical linkage of the activities might be necessary (JONSSON 2000, p. 66). For instance there may be several alternatives for the disassembly of an electric device depending of the condition of the device (e.g. rusted screws). OSim offers the possibility for modelling such a disjunction of the activities (see JONSSON 2000, pp. 83). Additionally, each node takes up a certain length of time. The generic approach, which forms the basis of the simulation tool OSim, allows each node of an activity network to be assigned to an arbitrary distribution. This creates the basics for the representation of processes with stochastic activity execution times.

\section{DISTRIBUTED EXECUTION TIMES}

The question then arises as to which type of distribution is particularly appropriate for the simulation of such activities with stochastic execution times. NEUMANN $(1975$, p. 213) recommends, based on practical project experiences, to choose a distribution for execution times within an activity network which fulfils three conditions: First of all, the distribution should be steady; second, the resultant activity execution times should be bounded above and below, and third, the realisation of the activity execution times should be concentrated around a certain value.

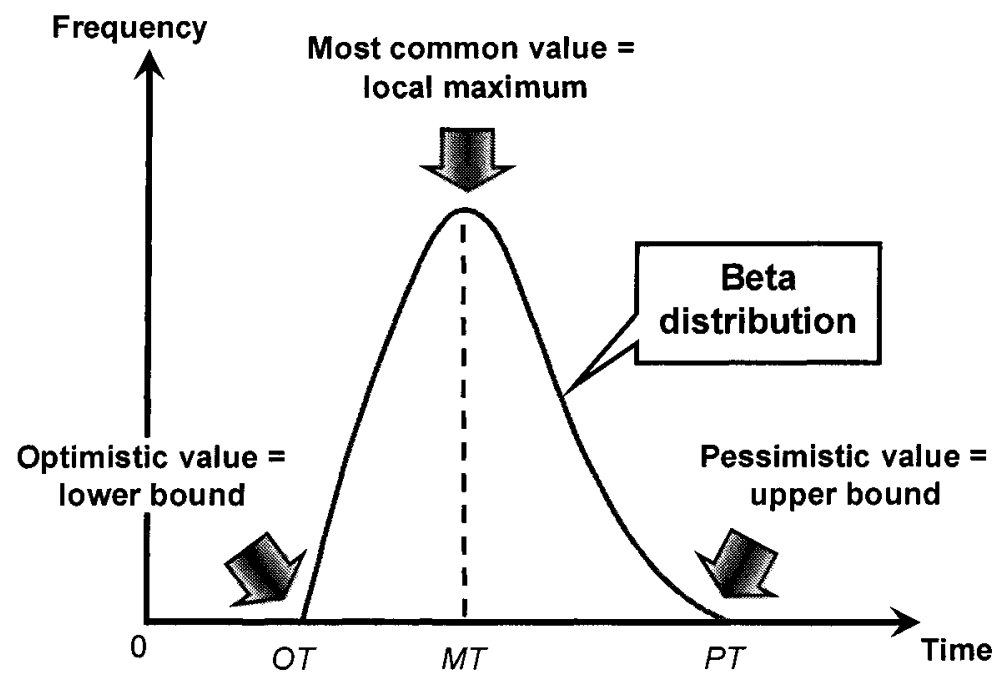

Figure 2. Modelling beta-distribution following the PERT methodology 
One distribution which complies with these conditions is the beta-distribution. It possesses an additional advantage: In accordance with the PERT methodology, stochastic activity times can be modelled using an optimistic value (OT), a pessimistic value (PT) and a most common value (See Figure 2; NEUMANN 1987, pp. 165).

These types of values can be determined relatively easily by interrogation or check lists during the data collection and modelling phase of the simulation model. Furthermore, with this kind of Beta distribution modelling, it is possible to get the execution times non-axially symmetric. Furthermore, KRAJEWSKI and RITZMAN (1999, p. 814) suggest that this approach is also suitable for the modelling of operation durations, which are subject to strong scattering.

The probability density function (pdf) of the Beta distribution is (NEUMANN 1975, pp. 213):

$$
\begin{aligned}
& f(t):= \begin{cases}\frac{(t-a)^{\alpha}(b-t)^{\beta}}{(b-a)^{\alpha+\beta+1} B(\alpha+1, \beta+1)} & \ldots \text { for } a \leq t \leq b \\
0, & \ldots \text { else }\end{cases} \\
& a:=O T, \quad b:=P T, \quad m:=M T
\end{aligned}
$$

The expected value EV can be estimated by:

$$
E V=\frac{O T+4 \cdot M T+P T}{6}
$$

\section{GENERATION OF BETA DISTRIBUTED RANDOM NUMBERS}

During a simulation run it is necessary to provide distributed random numbers for the simulated activities. The concept applied in OSim is based on the random number generator suggested by KLAUKE und PAWLICEK (1981, p. 43), which generates equally distributed random numbers according to the congruence method. In this sort of generator random numbers are created from their direct predecessor. This creates a reproducible list of random numbers for the simulation run, in which the same start number will always lead to the same series of random numbers. 
These equally distributed random numbers can be transformed into any statistical distribution. This is usually done through the inversion of probability transformation method, in which the inverse function of the cumulative distribution function (cdf) is used (NEUMANN 1977, pp. 313). For some distributions, however, among others the Beta distribution, it is very difficult to determine an elementary inverse function (LIEBL 1995, pp. 36).
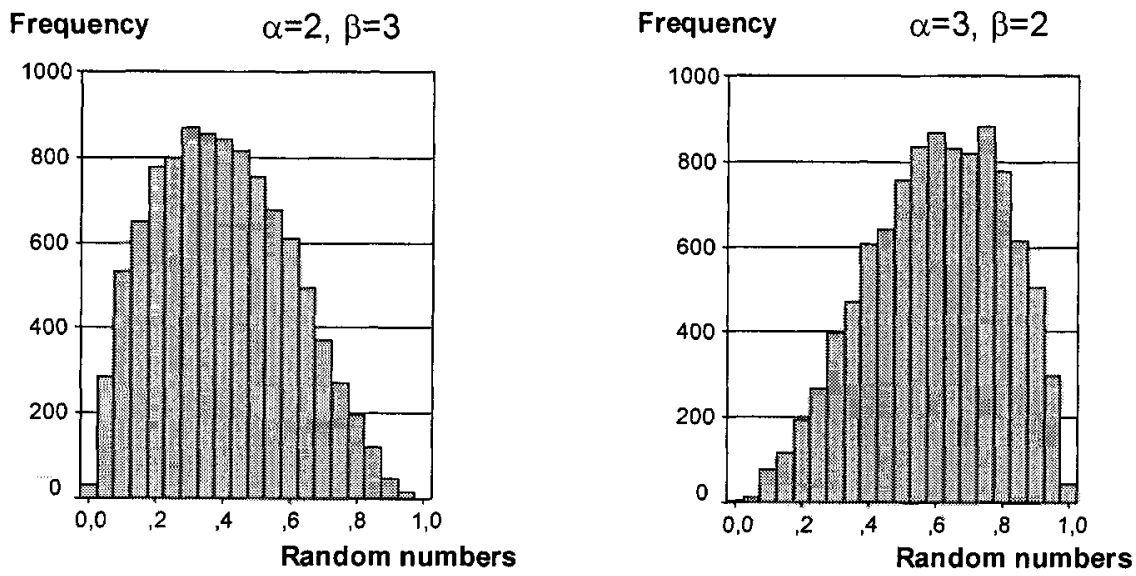

Random sample size $=10,000$

Figure 3. Generated beta-distributed random numbers in the interval $[0,1]$

To nonetheless be able easily to generate beta-distributed random numbers, OSim uses the rejection method for the transformation of equally distributed to beta-distributed random numbers (SCHMEISER 1977, p. 51). This method sorts out those random numbers which are not adequate for the corresponding distribution. In Figure 3 one can see different examples of beta-distributed random numbers in the interval between 0 and 1 , generated with the used beta-distributed random number algorithm suggested by DEVROYE (1986, K. 9.3-6).

\section{APPLICATION MODEL}

In the following a model, a real system will be used to investigate which effects the use of various distributions has upon the simulation results, and to what degree the beta-distribution is suitable for the modelling of stochastic execution times. The implemented model represents an industrial repair line of an industrial repair shop for electrical devices. 
The most important objective for the repairs in this application case is the achievement of a high service rate. This means that all repairs processed on a given day should be shipped back to the customer on the same day. If this is the case the service rate attains the optimum value of $100 \%$. Taking the type of the electrical device into consideration, a total of approx. 400 activity networks with variously distributed activity times were found. In the model, 6000 orders, the order programme for an entire month, were considered.

Optimistic, pessimistic and most common values were already available for each of the activity times to be modelled. Various distributions, which were later analysed in several simulation runs with various starting values from the random number generator, were modelled based on these values.

Assuming fixed execution times for the activities, the same key figures were achieved in every simulation run if the order programme is fixed. However, if one deposits distributions various key figure values will be determined for each simulation run, depending upon the start value for the random number generator. Based on these differing results, a result range can be derived for each key figure (Figure 4).

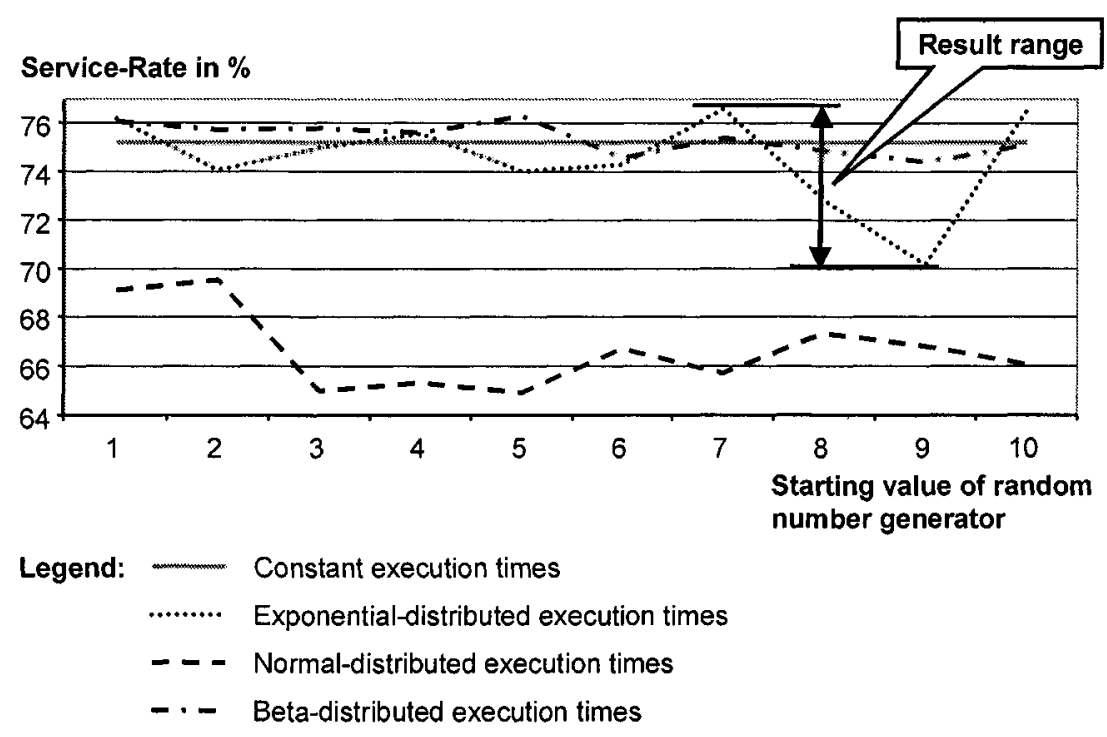

Figure 4. Creation of result ranges

Figure 5 represents the result range for the key figure "service rate". The result area for the beta-distribution is the smallest, implying that these results have the lowest degree of dispersion (standard deviation: for beta-distribution: 0.6 ; for exponential distribution: 1.6; for normal distribution: 1.9). The 
reason for this can be found, in the fact that the beta-distribution is bound. Values above or beneath the optimistic or pessimistic value are not present, in contrast to exponential and normal distributions. Incidentally, this bounding of the values corresponds with the experience that was made in the existing industrial repair line for electrical devices.

Furthermore, one can see that the beta-distribution value range encloses the simulated fixed values, whereas e.g. the exponential distribution tends to produce "poorer" results. This can be traced back to the fact that the exponential distribution is not bound above, and thus execution times which are "too long" must also be considered. Within the use of the normal distribution one can see that, generally, "poorer" results are attained for the service rate. Subsequently, it can be assumed that the use of this distribution would create execution times which tend to be too long. Further on, a normal distribution, which is the result of an addition of two independent normal distributions, has a greater statistical spread, i.e. the normal distribution is "broader" (see JACOD, PROTTER 2000, p. 116).

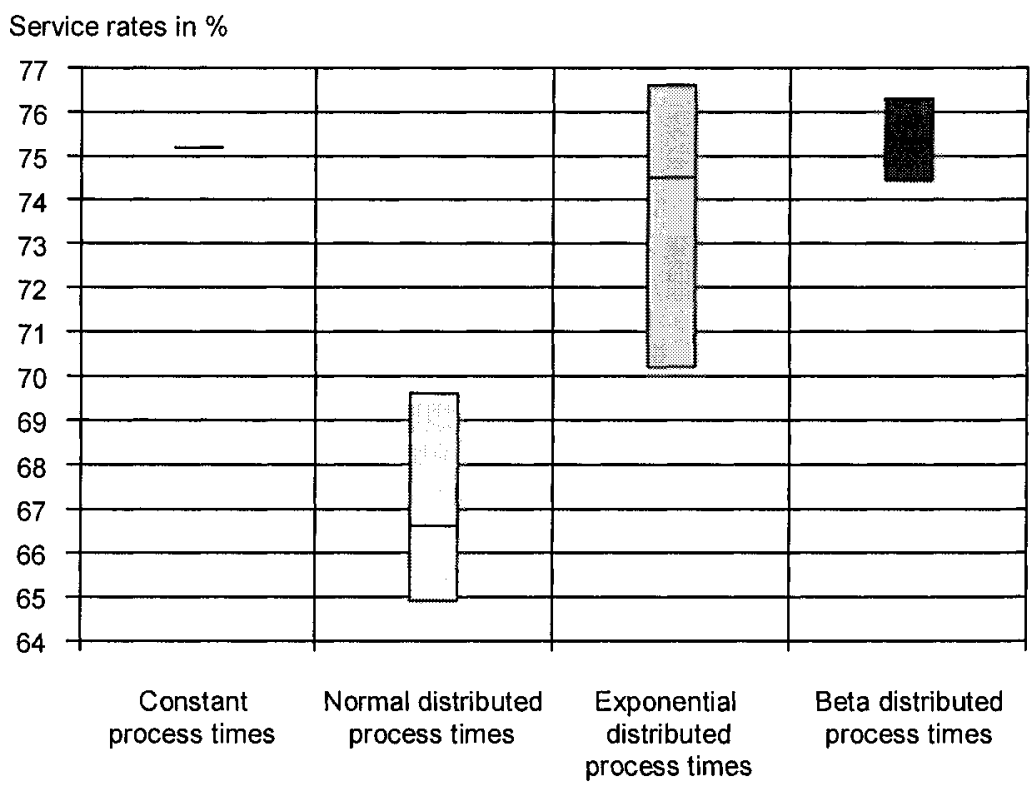

Figure 5. Ranges of service rates when simulating various distributions of execution times

Comparable correlations can also be seen with the key figure "utilisation" (see Figure 6), whereas the result area for the beta-distribution is the again smallest (standard deviation: for beta-distribution: 0.3; for exponential dis- 
tribution: 0.7 ; for normal distribution: 0.4). In this case, in particular the normal distribution results area lies considerably higher compared to values determined with constant times, which in turn indicates that a stronger equalisation of the operating times exists.

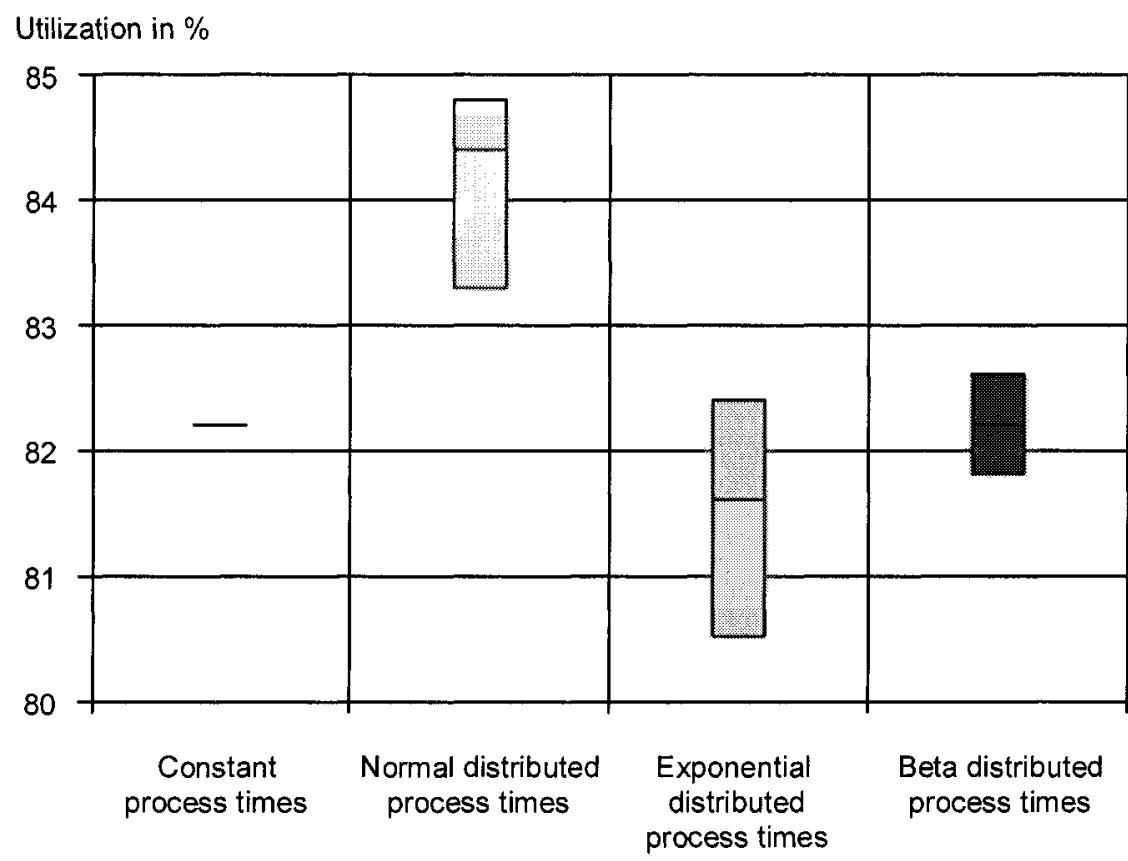

Figure 6. Ranges of utilisation when simulating various distributions of execution times

\section{SUMMARY}

The examination of the model at hand clearly showed that the beta-distribution is particularly well suited for the modelling of distributed execution times. This can be attributed to the ease of modelling and the resulting simplicity of the data collection. Furthermore, the results are closer to reality since the dispersion is smaller. If it can be guaranteed in a practical case that the optimistic or pessimistic values are neither exceeded nor under-run, it can then be safely expected that the results of the real system will also be in the result range the simulation model has predicted. 


\section{ACKNOWLEDGEMENTS}

This work was funded within the SAIDER-Project "Simulation aided improvement of disassembly and re-assembly processes" in cooperation with the SIM-SERV consortium (see also SAIDER 2004 for further information). SIM-SERV (2004) is financed by the EU under Framework Programme V "Competitive and Sustainable Growth".

\section{REFERENCES}

\section{DEVROYE, Luc:}

Non-Uniform Random Variate Generation.

Berlin, New York, Heidelberg u.a.: Springer Verlag, 1986.

GROBEL, Thomas:

Analyse der Einflüsse auf die Aufbauorganisation von Produktionssystemen. In:

Innovatives Arbeits- und Betriebszeitmanagement.

Eds.: ACKERMANN, Karl-Friedrich; HOFMANN, Mathias.

Frankfurt/M., New York: Campus Verlag, 1990, pp. 183-212.

JACOD, Jean; PROTTER, Philip:

Probability essentials.

Berlin et al.: Springer, 2000.

JONSSON, Uwe:

Ein integriertes Objektmodell zu durchlaufplanorientierten Simulation von

Produktionssystemen.

Aachen: Shaker Verlag, 2000.

(ifab-Forschungsberichte aus dem Institut für Arbeitswissenschaft und

Betriebsorganisation der Universität Karlsruhe, Vol. 21)

KLAUKE, Adolf; PAWLICEK, Jiri:

Die Erzeugung gleichverteilter Zufallszahlen für die Anwendung in stochastischen Simulationsmodellen.

In: Zeitschrift für Arbeitswissenschaft, Köln, 35(7NF)(1981)1, pp. 35-44.

KRAJEWSKI, Lee J.; RITZMAN, Larry P.:

Operations Management.

Reading, MA u.a.: Addison Wesley, 1999.

LIEBL, Franz:

Simulation.

München: R. Oldenbourg Verlag, 1995.

NEUMANN, Klaus:

Operations Research Verfahren. Volume 3: Graphentheorie, Netzplantechnik.

München, Wien: Carl Hanser Verlag, 1975.

NEUMANN, Klaus:

Operations Research Verfahren. Volume 2: Dynamische Optimierung, Lagerhaltung, Simulation, Wartschlangen.

München, Wien: Carl Hanser Verlag, 1977. 
NEUMANN, Klaus:

Netzplantechnik.

In: Grundlagen des Operations Research, Teil 2.

Hrsg.: GAL, Tomas.

Berlin et al.: Springer, 1987, S. 165-260.

\section{SAIDER:}

Sim-Serv - Sucess Stories: Simulation-aided improvement of disassembly and reassembly processes.

http://www.sim-serv.com/pdf/success_stories/member_22_story_75.pdf, 23.02.2004

SCHILLER, Emmerich F.:

Ein Beitrag zur adaptiv-dynamischen Arbeitsplanung in der Demontage.

Aachen: Shaker Verlag, 1998.

(ifab-Forschungsberichte aus dem Institut für Arbeitswissenschaft und

Betriebsorganisation der Universität Karlsruhe, Vol.14)

SCHMEISER, Bruce:

Methods for modelling and generating probabilistic components in digital computer simulation when the standard distributions are not adequate: A survey.

In: Proceedings of the 1977 Winter Simulation Conference.

Eds.: HIGHLAND, H. J.; SARGENT, R. G.; SCHMIDT, J. W.

Piscataway, NJ: The Institute of Electrical and Electronics Engineers, Volume 1, 1977, pp. 50-57.

ZÜLCH, Gert; FISCHER, Jörg:

An integrated object model as a world of model components for an activity network based simulation approach.

In: Simulation in Industry.

Eds.: BREITENECKER, Felix; HORTON, Graham; KAMPE, Gerald et. al.

Delft, Erlangen, San Diego: SCS-Europe, 2002, pp. 74-79.

ZÜLCH, Gert; FISCHER, Jörg; JONSSON, Uwe:

An integrated object model for activity network based simulation.

In: WSC'00 Proceedings of the 2000 Winter Simulation Conference.

Eds.: JOINES, Jeffrey A.; BARTON, Russel R.; KANG, Keebom et al.

Compact disk: WSC'00, 2000, pp. 371-380. 